\title{
A coordinated preventive care approach for healthy ageing in five European cities: a mixed-methods study of process evaluation components
}

DOI:

10.1111/jan.14181

\section{Document Version}

Accepted author manuscript

Link to publication record in Manchester Research Explorer

Citation for published version (APA):

Franse, C., Zhang, X., Grieken, A. V., Rietjens, J., Alhambra-Borras, T., Dura, E., Garces-Ferrer, J., Van Staveren, R., Rentoumis, T., Markaki, A., Bilajac, L., Vasiljev Marchesi, V., Rukavina, T., Verma, A., Williams, G., Clough, G., Koppelaar, E., Martijn, R., Mattace Raso, F., ... Raat, H. (2019). A coordinated preventive care approach for healthy ageing in five European cities: a mixed-methods study of process evaluation components. Journal of Advanced Nursing. https://doi.org/10.1111/jan.14181

Published in:

Journal of Advanced Nursing

\section{Citing this paper}

Please note that where the full-text provided on Manchester Research Explorer is the Author Accepted Manuscript or Proof version this may differ from the final Published version. If citing, it is advised that you check and use the publisher's definitive version.

\section{General rights}

Copyright and moral rights for the publications made accessible in the Research Explorer are retained by the authors and/or other copyright owners and it is a condition of accessing publications that users recognise and abide by the legal requirements associated with these rights.

\section{Takedown policy}

If you believe that this document breaches copyright please refer to the University of Manchester's Takedown Procedures [http://man.ac.uk/04Y6Bo] or contact uml.scholarlycommunications@manchester.ac.uk providing relevant details, so we can investigate your claim.

\section{OPEN ACCESS}


PROFESSOR HEIN RAAT (Orcid ID : 0000-0002-6000-7445)

Article type : Original Research: Empirical research - mixed methods

\section{A coordinated preventive care approach for healthy ageing in five European cities: a mixed- methods study of process evaluation components.}

Carmen B. FRANSE, $\mathrm{PhD}^{1}$; Xuxi ZHANG, MSc ${ }^{1}$; Amy VAN GRIEKEN, $\mathrm{PhD}^{1}$; Judith RIETJENS, $\mathrm{PhD}^{1}$; Tamara ALHAMBRA-BORRÁS, PhD²; Estrella DURÁ, PhD²; Jorge GARCÉS-FERRER, PhD ${ }^{2}$; Rob VAN STAVEREN, MSc ${ }^{3}$; Tasos RENTOUMIS, MSc ${ }^{4}$; Athina MARKAKI, MSc ${ }^{4}$; Lovorka BILAJAC, PhD ${ }^{5,6}$, Vanja Vasiljev MARCHESI, $\mathrm{PhD}^{5,7}$; Tomislav RUKAVINA, MD, PhD ${ }^{5,6}$; Arpana VERMA, MD, PhD ${ }^{8}$; Greg WILLIAMS, $\mathrm{MSc}^{8}$; Gary CLOUGH, MSc ${ }^{8}$; Elin KOPPELAAR, PhD ${ }^{9}$; Rens MARTIJN, MSc ${ }^{9}$; Francesco MATTACE RASO, MD, $\mathrm{PhD}^{10}$; Antonius J.J. VOORHAM, $\mathrm{PhD}^{9}$; Hein RAAT, MD, $\mathrm{PhD}^{1 *}$

\section{Affiliations:}

1-Erasmus University Medical Center, department of Public Health, Rotterdam, The Netherlands

2- Polibienestar Research Institute, University of Valencia, Valencia, Spain

3- Zorg Op Noord, Capelle aan den IJssel, The Netherlands

4- Alliance for integrated care, Athens, Greece

5-Faculty of Medicine University of Rijeka, Department of Social Medicine and Epidemiology, Rijeka, Croatia

6-Teaching institute of Public Health Primorsko-goranska County, Branch Office Opatija, Rijeka, Croatia

7-Faculty of Health Studies, University of Rijeka, Department of Public Health, Rijeka, Croatia 8- Manchester Urban Collaboration on Health, Centre for Epidemiology, Division of Population Health, Health Services Research and Primary Care, Manchester Academic Health Science Centre, The University of Manchester, Manchester, United Kingdom 9- Rotterdam University of Applied Sciences, Research Centre Innovation in Care, Rotterdam, The Netherlands 10-Erasmus University Medical Center, Section of geriatric medicine, department of Internal Medicine, Rotterdam, The Netherlands

* Corresponding author address: Hein Raat, Erasmus University Medical Center, department of Public Health, Wytemaweg 80, 3015 CN, Rotterdam, The Netherlands. E-mail: h.raat@erasmusmc.nl

This article has been accepted for publication and undergone full peer review (not applicable for Editorials) but has not been through the copyediting, typesetting, pagination and proofreading process, which may lead to differences between this version and the Version of Record. Please cite this article as doi: 10.1111/jan.14181 This article is protected by copyright. All rights reserved. 
Short running title: Process components of a healthy ageing care approach

\begin{tabular}{|c|c|}
\hline Criteria & Author Initials \\
\hline $\begin{array}{l}\text { Made substantial contributions to conception and design, or } \\
\text { acquisition of data, or analysis and interpretation of data; }\end{array}$ & $\begin{array}{l}C F, X Z, H R, A J J V, R v S, T A, T R, L B, \\
A V, G W\end{array}$ \\
\hline $\begin{array}{l}\text { Involved in drafting the manuscript or revising it critically for } \\
\text { important intellectual content; }\end{array}$ & $\begin{array}{l}\text { CF, XZ, AvG, JR, TA, ED, JGF, RvS, } \\
T R, A M, L B, V V M, T R, A V, G W, \\
\text { GC, EK, RM, AJJV, FMR, HR }\end{array}$ \\
\hline $\begin{array}{l}\text { Given final approval of the version to be published. Each } \\
\text { author should have participated sufficiently in the work to } \\
\text { take public responsibility for appropriate portions of the } \\
\text { content; }\end{array}$ & $\begin{array}{l}\text { CF, XZ, AvG, JR, TA, ED, JGF, RvS, } \\
T R, A M, L B, V V M, T R, A V, G W, \\
\text { GC, EK, RM, AJJV, FMR, HR }\end{array}$ \\
\hline $\begin{array}{l}\text { Agreed to be accountable for all aspects of the work in } \\
\text { ensuring that questions related to the accuracy or integrity of } \\
\text { any part of the work are appropriately investigated and } \\
\text { resolved. }\end{array}$ & $\begin{array}{l}C F, X Z, A v G, J R, T A, E D, J G F, \text { RvS, } \\
T R, A M, L B, V V M, T R, A V, G W, \\
G C, E K, R M, A J J V, F M R, H R\end{array}$ \\
\hline
\end{tabular}

Acknowledgements: We would like to thank all participating older persons and all organizations and professionals involved in the UHCE project for their contributions to the UHCE study.

Funding statement: This work was supported by the European Union, CHAFEA, third health programme, grant number 20131201. XZ is supported by a China Scholarship Council (CSC) PhD Fellowship for her PhD study in Erasmus MC, Rotterdam, the Netherlands. The scholarship file number is 201706010358, CSC URL: [http://www.csc.edu.cn/].

Conflict of interest: No conflict of interest has been declared by the author(s).

\section{ABSTRACT}

Aims: To evaluate specific process components of the Urban Health Centres Europe approach; a coordinated preventive care approach aimed at healthy ageing by decreasing falls, polypharmacy, loneliness and frailty among older persons in community settings of five cities in the United Kingdom, Greece, Croatia, the Netherlands and Spain.

Design: Mixed-methods evaluation of specific process components of the Urban Health Centres Europe approach: reach of the target population, dose of the intervention actually delivered and received by participants and satisfaction and experience of main stakeholders involved in the approach.

This article is protected by copyright. All rights reserved. 
Methods: The Urban Health Centres Europe approach intervention consisted of a preventive assessment, shared-decision making on a care plan and enrolment in one or more of four coordinated care-pathways that targeted falls, polypharmacy, loneliness and frailty. Quantitative data from a questionnaire and quantitative/qualitative data from logbooks were collected among older persons involved in the approach. Qualitative data from focus-groups were collected among older persons, informal caregivers and professionals involved in the approach. Quantitative data were analysed by means of descriptive statistics and multilevel logistic regression models. Qualitative data were analysed through thematic analysis.

Results: Having limited function was associated with non-enrolment in falls and loneliness care-pathways (both $\mathrm{P}<0.01$ ). The mean rating of the approach was 8.3/10 (SD 1.9). Feeling supported by a care professional and meeting people were main benefits for older persons. Mistrust towards unfamiliar care providers, lack of confidence to engage in care activities and health constraints were main barriers towards engagement in care.

Conclusions: Although the Urban Health Centres Europe approach was received generally positively, health constraints and psychosocial barriers prevented older person's engagement in care.

Impact: coordinated preventive care approaches for older community-dwelling persons should address health constraints and psychosocial barriers that hinder older person's engagement in care.

Trial registration: ISRCTN registry number is ISRCTN52788952. Date of registration is $13 / 03 / 2017$

Keywords: coordinated care, frailty, nurses, older persons, prevention, primary care, process evaluation, mixed-methods study

This article is protected by copyright. All rights reserved. 


\section{INTRODUCTON}

Europe has the highest proportion of persons over 65 years compared with any other continent (United Nations Department of Economic and Social affairs, 2017). As the number of older persons is increasing, there will be relatively fewer beds available in inpatient care facilities. Because of this, it is important to have a well-functioning primary care system that promotes healthy ageing among older persons. The European Union has identified priority areas for healthy ageing, which are: polypharmacy, falls and frailty (European Innovation Partnership on Active and Healthy Ageing, 2013). These are highly prevalent among older persons and are associated with negative health outcomes and higher care use (Gobbens, van Assen, Luijkx, \& Schols, 2012; Morrison, Fan, Sen, \& Weisenfluh, 2013; Muhlack, Hoppe, Weberpals, Brenner, \& Schottker, 2017). Loneliness is another large problem among older persons; around 20-30\% report loneliness (Yang \& Victor, 2011). Loneliness has been associated with frailty (Herrera-Badilla, Navarrete-Reyes, Amieva, \& Avila-Funes, 2015) and a fall in the previous year (Hajek \& Konig, 2017). Hence, the co-occurrence of these and other health problems is common (Navickas, Petric, Feigl, \& Seychell, 2016; Onder et al., 2007)

Coordinated preventive care interventions which integrate health and social care services have been proposed to address health problems among older persons (Kringos et al., 2015;

Nolte et al., 2009). These interventions usually include a preventive multidimensional assessment of health, development of a care plan and coordinated care (Huss, Stuck, Rubenstein, Egger, \& Clough-Gorr, 2008; Markle-Reid, Browne, \& Gafni, 2013; Metzelthin, van Rossum, et al., 2013). This care plan is often made through a process of shared decisionmaking, where the patient is involved in care decisions (Legare et al., 2011). Care coordination is typically done by a nurse to alleviate the workload for the general practitioner.

This article is protected by copyright. All rights reserved. 


\section{Background}

Evidence for a positive effect of coordinated preventive care interventions on quality of life and independent functioning among older persons is mixed (Beswick et al., 2008; MayoWilson et al., 2014; Ruiz et al., 2017; Wind et al., 2018). This may be explained by differences in groups reached by the intervention, fidelity to the intervention and context of implementation. However, a recent study revealed that coordinated preventive care studies often do not report how such specific aspects of the intervention are carried out (Smit et al., 2017). Insight in these so-called 'process components' could increase the understanding of underlying reasons for why some studies do find positive effects while another do not. Steckler and Linnan have developed a framework to study process components for public health interventions (Saunders, Evans, \& Joshi, 2005; Steckler, 2002). In this framework, process components which are evaluated include: reach of the target population, dose of the intervention actually delivered to and received by participants and satisfaction of main stakeholders with the intervention (Steckler, 2002). The Stecklar and Linnan framework is recommended for the development and reporting of complex interventions (Mohler, Kopke, \& Meyer, 2015).

The Urban Health Centres Europe approach (UHCE-approach) was a preventive coordinated care approach aimed at promoting healthy ageing by decreasing falls, polypharmacy, loneliness and frailty among community-dwelling older persons (Franse et al., 2017). The UHCE-approach consisted of a preventive assessment of fall risk, polypharmacy, loneliness and frailty and, only if the person had a need or indication for care, shared-decision making on a care plan and enrolment in coordinated care-pathways (Franse et al., 2018). The UHCEapproach showed promising, but minor positive effects in tackling recurrent falls and frailty and promoting physical health-related quality of life and mental well-being compared with care as usual (Franse et al., 2018). Further, only 54\% of older persons enrolled in care- 
pathways. As part of the UHCE-study, process components of the implementation of the UHCE-approach were evaluated as proposed by Steckler and Linnan. By evaluating these process components, we want to improve the understanding of the reasons for the low enrolment and minor effects found in the UHCE-approach. The current evaluation could also aid the future development and implementation of similar interventions.

\section{THE STUDY}

\section{Aims}

The aim of this study is to evaluate specific process components of the UHCE-approach among older persons in community settings of five European cities. The following research questions are answered:

1) What population was reached by the UHCE-approach?

2) What dose of the intervention was actually delivered and received and by which participants?

3) What was the satisfaction and experience of main stakeholders involved in the UHCEapproach?

\section{Intervention}

The development of the UHCE-approach intervention has been previously described (Franse et al., 2018; Franse et al., 2017). A general template for the UHCE-approach was developed based on systematic literature searches of evidence-based interventions and focus group discussions with main stakeholders. The general UHCE-template consisted of three stages (Figure 1).

This article is protected by copyright. All rights reserved. 
The first stage involved a preventive health assessment at the older person's home or at a health centre. This was done to identify if there was a need or indication for follow-up carepathway (s). For this purpose, a short uniform assessment form was developed, which was to be used in all cities. The assessment consisted of instruments that had been previously validated. These instruments assessed: 1) risk of falling; based on a protocol by Dutch safety research institute (Veiligheid.nl); 2) polypharmacy; based on using five or more different medicines (Barenholtz Levy, 2003) and/or difficulty in taking medications as prescribed; 3) loneliness; based on Jong-Gierveld loneliness scale (De Jong Gierveld \& Van Tilburg, 2010); and 4) frailty; based on the Tilburg Frailty Indicator (Gobbens, van Assen, Luijkx, WijnenSponselee, \& Schols, 2010). The assessment was piloted in at least five older persons in each city. For the questions that were not interpreted correctly, minor changes were made.

The second stage of the UHCE-approach consisted of shared-decision making. When the results of the assessment indicated a need for follow-up care, a care plan was to be developed together with the older person, this was done to promote his/her involvement in carepathways. The UHCE-template recommended discussing the results of the assessment at least between the older person, the person in charge of care coordination and the physician.

Because informal caregivers can have an important role in the older person's care, care teams were encouraged to ask the older person to involve an informal caregiver such as a partner or relative in shared decision-making.

The third stage of the UHCE-approach consisted of referral to care-pathways. After a shareddecision on an individualized care plan was made, each participant was to be referred to carepathways according to their indication and preferences. The main care-pathways were: 1) fall prevention actions; 2) actions addressing polypharmacy (adherence and/or appropriate prescribing actions); 3) actions addressing loneliness; and 4) frailty and other medical actions; frailty actions and other medical care which the healthcare provider deemed 
necessary and which did not fall under care-pathways 1-3 was given in this care-pathway. The general template of the UHCE-approach included evidence-based interventions for each care-pathway based on systematic literature searches, which were to be used by the cities. The care coordinator was asked to monitor the progress of each individual care plan under the supervision of a physician (Franse et al., 2018).

\section{Ethical considerations}

Ethical committee procedures were followed in all cities and approval was provided (Franse et al., 2018). Written consent was obtained from all participants. The study was registered in the ISRCTN registry under number ISRCTN52788952.

\section{Context \& implementation}

The general template of the UHCE-approach was subsequently implemented in the context of primary care and community settings in five European cities (Greater Manchester, United Kingdom; Pallini, Greece; Rijeka, Croatia; Rotterdam, the Netherlands; and Valencia, Spain). The place of assessment, type of care-pathways, staff involved and context of each of the five participating cities are described in more detail in Table 1.

In all cities, except for Pallini, general practices were involved in the UHCE-approach. In Pallini, the UHCE-approach was provided by a health team from the municipal health centre newly employed for this study. The health assessment took place at the person's home in all cities except for Pallini, where the assessment took place at a community centre. In Rotterdam and Manchester, the UHCE-approach made use of existing care interventions. In Rijeka and Valencia, some new care provisions were newly developed and in Pallini all care provisions were newly developed.

This article is protected by copyright. All rights reserved. 
Falls care-pathways varied among settings, including group-based exercise programs, home adjustments and physiotherapy. In Rijeka and Valencia persons who had a frailty indication were offered to enrol in the falls care-pathway. In Rijeka and Pallini, the polypharmacy carepathway included a self-managed medication adherence application. In the other settings, persons entering this care-pathway received a medication review by a pharmacist. The loneliness care-pathway included group-based activities and support groups. No additional monetary incentives were provided to staff in existing care. In settings where new care provisions were developed, the staff was hired on a voluntary basis or sometimes compensated. The participants received no monetary incentives. For some of the interventions, participants borrowed materials that were needed for care activities.

\section{Design}

We applied a convergent mixed-methods evaluation design (Creswell \& Plano Clark, 2018) alongside the effect evaluation of the UHCE-approach. This was done in all cities between May 2015 and June 2017. Quantitative and qualitative data were collected and analysed separately.

\section{Participants}

Older persons and informal caregivers

The target population consisted of persons living independently, aged 75 years or older, who were, according to their physician, able to participate in a care-pathway for at least 6 months. This timeline was chosen because the care pathways were to last at least 6 months. In two cities; Pallini and Valencia, the age of the population was lowered to 70 years or older due to difficulties encountered during recruitment. Older persons who participated were recommended to involve an informal caregiver, particularly in shared decision-making, as described earlier. Older persons were not eligible to participate if they were not able to 
comprehend information in the local language or if they were unable to cognitively evaluate the risks/benefits of participation and were not expected to make an informed decision regarding participation, according to their physician (Franse et al., 2017). We aimed for a purposeful sample of 250 older persons in each city, as previously described (Franse et al., 2017).

Professionals

In each city, health and social care professionals participated in the UHCE-approach. Care decisions were made by a physician, together with a care coordinator, older person and sometimes an informal caregiver. Other professionals involved in the care-pathways were physiotherapists, occupational therapists, physical educators, psychologists, social workers, pharmacists and volunteers, depending on context as described in Table 1.

\section{Data collection}

Specific process components were evaluated: reach of the target population, dose of the intervention actually delivered and received by participants and satisfaction and experience of main stakeholders with the intervention as proposed by Stecklar and Linnan (Steckler, 2002). Table 2 presents an overview of process evaluation components for each study question and the way these were measured in the study.

Questionnaire

A quantitative questionnaire was developed mainly for the purpose of the effect evaluation of the UHCE-approach. It was administered to older persons at baseline and at follow-up after 12 months. To study reach and dose received; characteristics of participants who were lost to follow-up and characteristics of participants who did not enrol in care-pathways (Table 2; question 1.2 and 2.2), we used 10 items included in the baseline questionnaire: age (in years), sex (male/female), living situation (alone/not alone), education level (low/high; based on 
International Standard Classification of Education; ISCED) (Organisation for Economic \& Development, 1999), function (limited/not limited; based on Global Activity Limitation Index; GALI) (Berger et al., 2015; van Oyen, Van der Heyden, Perenboom, \& Jagger, 2006) and mental health (poor/good; based on 5-item mental well-being scale of the SF-36) (Berwick et al., 1991).

To study satisfaction with the UHCE-approach (Table 2; question 3.1), we used 5 items included in the follow-up questionnaire. Four items measured whether persons agreed on being satisfied with each of the three UHCE stages on a five-point Likert scale. Answers were categorized into 'agree/strongly agree' and 'neither agree nor disagree/disagree/strongly disagree'. A final item rated person's satisfaction with the UHCE-approach on a scale from 1 to 10 .

Items that were not available in local language (age, sex, living situation and satisfaction with the UHCE-approach) were developed in English and translated into local languages. Items were translated into the local languages and backward into English. Backward English translations were discussed among the study team and translation was adapted when needed. In each city, the questionnaire was piloted in at least five older persons. When questions were misinterpreted by participants, minor changes were made.

\section{Logbooks}

To study dose delivered to and received by the participants (Table 2; question 2.1 and 2.3), a logbook was developed for all cities. This logbook was kept for each older person involved in the UHCE-approach. In this logbook, quantitative information of the delivery and involvement of the older person in the three stages of the UHCE-approach was kept: 1.

Whether or not a health assessment took place and whether the participant had an indication for any care-pathways, 2 . Whether or not shared decision making took place and 3. Whether 
or not the participant followed any care-pathways. Additionally, an open-ended qualitative question on the reason for not enrolling into any care-pathways was included. After 6 months at least, the care coordinator documented (if needed contact was made with either the participant or responsible health care provider) whether the three stages of the UHCEapproach were delivered. The paper logbooks were subsequently entered into an electronic data-entry form. Electronic data were checked for missing/incorrect data.

Focus groups

To study the experience of main stakeholders involved (Table 2; question 3.2), focus groups (Harrell, Bradley, National Defense Research, \& Rand, 2009) of 40 minutes to 1 hour each were held around the time of the follow-up assessment 12 months after baseline with older persons, informal caregivers and professionals. Semi-structured topic guides (Table S1) were developed which included the following topics: 1) overall experience with the UHCEapproach; 2) experience with the health assessment and care-pathways; and 3) experience with shared-decision making. For each of these topics, the guide included probe questions about benefits, barriers and improvements participants identified. In Manchester, two focus groups with five older persons/informal caregivers each were organized, in all other cities one focus group with 5 older persons/informal caregivers was organized. Older persons and caregivers with the following criteria were selected: being physically and mentally able to participate in the focus group and enrolled (or the person they cared for enrolled) in at least one care-pathway. In each city except Manchester, one focus group with four to six social and health care professionals was organized. This number allowed us to select professionals with varied professions who had been actively involved in the UHCE-approach. In Manchester, two health professionals were interviewed. In total: 26 older persons, four informal caregivers and 22 professionals were included (7 nurses, 4 general practitioners/physicians, 2 physical/occupational therapists, 2 social workers, 2 trained 
assistants, 1 physical education teacher, 1 pharmacist, 1 volunteer, 1 care manager, 1 municipality officer). Table $\mathrm{S} 2$ describes the numbers by city. The focus group discussions and in-depth interview were recorded, transcribed into the local language and translated into English if applicable.

\section{Data analysis}

Quantitative data were summarised using descriptive statistics (frequencies, means and percentages). Characteristics of persons included at follow-up and persons who dropped out were compared by means of chi-square tests for categorical variables and one-way ANOVA for continuous variables. We further compared characteristics of persons who enrolled in a specific care-pathway (falls, polypharmacy, loneliness and frailty) with persons who did not enrol in that care-pathway but had an indication to receive that care-pathway. For this purpose, multilevel random-intercept logistic regression was used because data were clustered by city (Twisk, 2013). We built 4 separate models for each care-pathway where we analysed the association of independent variables age, sex, living situation, education level, function and mental health with dependent variable non-enrolment. We corrected the effect estimates for all factors as well as clustering effects by city. We considered a P-value of 0.05 or lower to be statistically significant. All quantitative analyses were performed using SPSS version 23.0 (IBM SPSS Statistics for Windows, Armonk, NY: IBM Corp).

For the qualitative data from the focus groups and logbooks, the thematic analysis method was used (Boyatzis, 2009). Focus group transcripts were read multiple times by CF and XZ and meaningful overarching themes and subthemes were identified and summarized in a coding table. The coding table was discussed among the authors and refined. Subsequently, applicable quotes from the transcripts were entered into the coding table and categorized according to subtheme. Overarching themes confirmed topics in the topic guide that was used for the focus groups: benefits/barriers of the health assessment, benefits/barriers of the care- 
pathways and recommendations for improvement. Meaningful subthemes emerged from the raw data (e.g. under the overarching theme 'barriers of the care-pathways', subthemes 'mistrust' and 'embarrassment' emerged). In total, five overarching themes and 16 subthemes arose from the focus groups with older persons and informal caregivers (Table S3). From the focus groups with professionals five overarching themes and 24 subthemes arose (Table S3). Qualitative logbook data on the older person's reason (s) for not enrolling into any carepathways were coded into meaningful themes in an excel sheet by CF. Subsequently, XZ coded the data into the themes developed by CF. Coding by the two authors was compared and disagreements in coding were discussed and resolved. If necessary, themes were refined by discussion between authors.

\section{Rigour}

The design of this study was based on a theoretical framework for process evaluations of public health interventions developed by Stecklar and Linnan (Steckler, 2002). Using an established theoretical framework in the development and reporting of complex interventions improves transparency (Mohler et al., 2015). We used a combination of quantitative and qualitative methods to study process components. This has the benefit of being able to confirm findings with different methods, thus increasing validity (Foss \& Ellefsen, 2002). The qualitative data analysis was performed independently by two researchers and compared with increase the reliability of the coding of qualitative information (Boyatzis, 2009).

\section{RESULTS}

\section{Reach}

Overall, 2,825 persons were invited to participate in the UHCE-approach and 1,215 persons (43.0\%) accepted the invitation and completed the baseline health assessment (Table 3). Of 
these persons, 986 persons $(81.2 \%)$ completed the follow-up questionnaire at 12 -month follow-up. A comparison of persons included at follow-up ( $\mathrm{N}=986)$ with persons who dropped out of the study after baseline $(\mathrm{N}=229)$ did not indicate significant differences in terms of sex $(\mathrm{P}=0.164)$, living situation $(\mathrm{P}=0.519)$, function $(\mathrm{P}=0.593)$ and mental health $(\mathrm{P}=0.463)$, but these persons were older $(\mathrm{P}<0.001)$ and lower educated $(\mathrm{P}=0.001)$.

\section{Dose delivered and received}

Of the 986 persons who received the UHCE-approach, according to the UHCE-template; $80.5 \%$ had an indication; $50.9 \%$ had a fall risk indication, $50.2 \%$ had a polypharmacy indication, $28.4 \%$ had a loneliness indication and 54.0\% had a frailty indication (Table 3). Indications for care-pathways, as reported in logbooks differed from those proposed in the UHCE-template; $85.6 \%$ had an indication. Having an indication as reported in logbooks varied between $74.1 \%$ in Manchester to $100 \%$ in Rijeka. Shared-decision making was done with almost all participants. In total, 520 persons $(53.6 \%)$ enrolled in any of the carepathways. Enrolment in any care-pathway varied between $99.5 \%$ in Rijeka to $14.6 \%$ in Rotterdam. Across all cities; $28.6 \%$ enrolled in the falls care-pathway, $23.0 \%$ enrolled in the loneliness care-pathway, $13.7 \%$ enrolled in the polypharmacy care-pathway and $9.9 \%$ enrolled in the frailty/medical care-pathway.

Characteristics associated with non-enrolment in care-pathways among older persons involved in the UHCE-approach are presented in Table 4. Limited function was positively associated with non-enrolment in the falls and loneliness care-pathways $(p<0.01)$. Female gender was positively associated with non-enrolment in the polypharmacy care-pathway, but negatively associated with non-enrollment in the loneliness care-pathway $(\mathrm{p}<0.05)$.

The reasons older persons reported for why they did not enroll in care-pathways are presented in Table 5. Of the 466 persons who were non-enrolled, 326 (70.0\%) did have an indication 
for a care-pathway according to the logbooks. Of those, 173 persons reported a reason for non-enrolment; 91 from Manchester, 45 from Rotterdam, 29 from Pallini and 8 from

Valencia. Most persons (28.3\%) reported that they wanted to deal with health problem themselves, many also reported already being involved in other care or exercise $(22.0 \%)$. All but one person who reported these reasons were from Manchester or Rotterdam. In all cities, persons reported that health problems prevented participation (11.6\%).

\section{Satisfaction and experience}

Satisfaction with the UHCE-approach among older persons is reported in Table 6. Persons were generally satisfied with the UHCE-approach. Overall, $82.1 \%$ of persons in all cities felt they had benefitted from the health assessment and $85.4 \%$ of persons felt it was worth the time and effort. The mean rating of the UHCE-approach was $8.3(\mathrm{SD}=1.9)$ out of 10 , ranging from $6.5(\mathrm{SD}=2.4)$ in Pallini to $9.3(\mathrm{SD}=1.2)$ in Manchester.

In the focus groups, several benefits of the UHCE-approach for older persons and care professionals were identified (Table S3). A benefit according to older persons and professionals, which was identified in all cities, was that older persons valued the feeling that someone looked out for them; either the care coordinator or care professionals in the carepathways. Another benefit according to older persons and professionals in most cities was that older persons valued meeting other people. The group-based care-pathways of UHCE had given older persons involved in these activities the opportunity to meet others. An older woman in Valencia commented on the social support group: "I liked it a lot, it helped me to open up to people". A benefit according to older persons and professionals in several cities was that results from the assessment and contact with care professionals had motivated older persons to take action regarding their health. Several benefits for care professionals were identified in the focus group with care professionals in Rotterdam. A key benefit was that 
using a structured preventive assessment for recording older person's health had aided in future care decisions, because care professionals were able to look back in the records.

Some barriers and recommendations were also identified (Table S3). One of the main barriers for older person's engagement in care according to care professionals in all cities was mistrust among older persons towards unfamiliar care professionals and activities. A recommendation made by care professionals in several cities which related to this was the importance of building a trusted relationship with clients. A health professional in Rotterdam said: "You have to invest in it [the relationship], once the trust is there then the older person will follow your advice”. Another main barrier according to older persons in most cities was feeling embarrassed or lacking confidence about engaging in activities. An older woman in Valencia said: "I think I told you of my fall, but since then I have just lost complete confidence in going anywhere". An older man in Manchester explained: "There were clubs to join but I just didn't have the confidence, when you live on your own you get introverted". A barrier which was identified by both older persons and health professionals in all cities were health constraints of older persons. This also appeared to prevent engagement in carepathways that required more activity or travel. A recommendation that was made by care professionals in Rijeka, was to further adapt preventive care activities to needs of specific groups of older persons such as persons with chronic illnesses. Specific barriers for care professionals in several cities were time constraints and unfamiliarity of health professionals in collaborating with social care professionals. Finally, the most common recommendation according to older persons and health professionals in Pallini, Rijeka and Valencia, where activities were not embedded in existing care, was to continue activities beyond the project.

This article is protected by copyright. All rights reserved. 


\section{DISCUSSION}

In this study, we examined what dose of a coordinated preventive social and health care approach for older persons was delivered and received, which persons were reached and what their experience was with the approach. The UHCE-approach was received generally positively. However, having limited function was associated with non-enrolment in specific care-pathways of the approach. Feeling supported by a care professional was mentioned as a benefit for older persons. Mistrust towards unfamiliar care providers and lack of confidence to engage in certain care activities were mentioned as barriers.

In a previous study they found minor effects of the UHCE-approach on the lifestyle, health and quality of life of older persons and hypothesized that this was due to only around half of the persons in the intervention group enrolling in care-pathways (Franse et al., 2018).

Quantitative and qualitative results from the current study imply that persons in poor health might have enrolled less often, especially in falls and loneliness care-pathways. Interventions in the falls and loneliness care-pathways required persons to move to the training location and included active activities such as balance and strength training or social group activities. Persons who were limited in function might have not been able to participate in these activities. In most cities, care in the other care-pathways for frailty and polypharmacy consisted of further assessment or referral to other care services. Which means these pathways required a less active involvement of older persons. Future interventions should develop strategies to reach older persons with limited functioning. Further adapting interventions to needs of groups with specific health problems were recommended by care professionals in this study. This is supported by findings from a large meta-analysis of complex care interventions which found no benefits of any specific type of intervention and recommended tailoring of interventions to client needs (Beswick et al., 2008). In Rotterdam and Manchester, where enrolment into care-pathways was particularly low, many persons 
reported wanting to solve health problems themselves and already being involved in other care as reasons for non-enrolment. As explained earlier (Franse et al., 2018), regular care for older persons in Manchester and Rotterdam was of high standard and the added benefit of the UHCE-approach might have been small in these settings (Beswick et al., 2008).

Older persons were generally satisfied with the UHCE-approach. A main benefit for older persons was feeling that a care professional looked out for them. Feeling supported by and experiencing a better relationship with the care provider has also been reported in other coordinated care interventions (Baxter \& Markle-Reid, 2009; Metzelthin, Daniels, et al., 2013; Poot, Caljouw, Waard, Wind, \& Gussekloo, 2016). Trust appears to be the foundation of the relationship between care provider and older person and has an impact on the acceptance of offered care (Bindels, Cox, Widdershoven, van Schayck, \& Abma, 2014; Muntinga et al., 2016; van Kempen et al., 2012). Also, in our study, mistrust among older persons towards unfamiliar services and care providers was a main barrier towards participation in care. Psychosocial reasons were also a barrier towards care uptake in our study. Some older persons did not want to engage in activities that could put them in awkward social situations. Others did not feel confident enough to travel to activity locations because they were afraid of falling. It is therefore important for care professionals to focus on these psychosocial factors that influence care decisions. Even more so, because older persons themselves appear to prefer that care professionals focus on their psychosocial context (van Kempen et al., 2012).

There were differences between the health assessment indications as proposed in the general template and as used by cities. Cities reported sometimes using additional instruments or basing decisions on further clinical judgement. Cross-cultural adaptation of health assessment instruments could improve medical decision-making, such as has been done for the Tilburg Frailty Indicator in some countries (Coelho, Santos, Paul, Gobbens, \& Fernandes, 2015; 
Uchmanowicz et al., 2014). The extent of integration of the UHCE-approach in the existing care system differed among cities. In Pallini, Rijeka and Valencia existing care was not available or referral to existing care was difficult. This could have had an impact on the sustainability of the UHCE-approach. Indeed, both participants and professionals in these cities mentioned they wished activities would continue beyond the project.

\section{Strengths and limitations}

The main strength of the current study is that we did an extensive evaluation of process components based on a theoretical framework proposed by Stecklar and Linnan (Steckler, 2002). By combining quantitative and qualitative methods we were able to deepen the understanding of the implementation of the UHCE-approach. This study also has some limitations. First, logbooks were completed by staff involved in the UHCE-approach. This might have caused a bias and positive reporting of the execution of logbook components. For example, cities reported that shared-decision making was done in almost $100 \%$ of cases. However, it was unclear how and to what extent the older person was involved in this process. Perhaps the definition of shared-decision making has been interpreted differently by cities. Secondly, older persons included in the focus groups might have been those that were most positive about the UHCE-approach as these persons were selected by care professionals involved in the study. Third, there were many missings for the questions on satisfaction of the UHCE-approach. Persons who did not answer could have thought these questions were not applicable to them because they were less involved in the UHCE-approach. The responses could have therefore been biased towards the more active participants who might have been more positive about the UHCE-approach. Further, although questions on satisfaction were translated from English to local languages and back translated, there might have been crosscultural differences in the interpretation of these questions. Last, we did not include a 
representative number of informal caregivers in the focus groups. Having the perspective of this group would have strengthened our findings.

\section{Conclusions}

Although coordinated prevented care appears to be received positively, there may be barriers that hinder person's engagement in care. Care activities that require transport or a higher level of activity might not reach older persons who are limited in their functioning and should be adapted for this group of older persons. Mistrust towards unfamiliar care providers and lack of confidence to engage in certain care activities are main barriers towards engagement in care among older persons. It is therefore important for care professionals to build a trusted relationship with their older clients and focus on psychosocial barriers that might affect their care decisions.

\section{Conflict of interest statement}

The authors declare that they have no competing interests

\section{REFERENCES}

Barenholtz Levy, H. (2003). Self-administered medication-risk questionnaire in an elderly population. Ann Pharmacother, 37 (7-8), 982-987.

Baxter, P., \& Markle-Reid, M. (2009). An interprofessional team approach to fall prevention for older home care clients 'at risk' of falling: health care providers share their experiences. Int J Integr Care, 9, e15.

Berger, N., Van Oyen, H., Cambois, E., Fouweather, T., Jagger, C., Nusselder, W., \& Robine, J. M. (2015). Assessing the validity of the Global Activity Limitation 
Indicator in fourteen European countries. BMC Med Res Methodol, 15, 1. doi:10.1186/1471-2288-15-1

Berwick, D. M., Murphy, J. M., Goldman, P. A., Ware, J. E., Jr., Barsky, A. J., \& Weinstein, M. C. (1991). Performance of a five-item mental health screening test. Med Care, 29 (2), 169-176.

Beswick, A. D., Rees, K., Dieppe, P., Ayis, S., Gooberman-Hill, R., Horwood, J., \& Ebrahim, S. (2008). Complex interventions to improve physical function and maintain independent living in elderly people: a systematic review and meta-analysis. Lancet, 371 (9614), 725-735. doi:S0140-6736 (08)60342-6 [pii]

10.1016/S0140-6736 (08)60342-6

Bindels, J., Cox, K., Widdershoven, G., van Schayck, O. C., \& Abma, T. A. (2014). Care for community-dwelling frail older people: a practice nurse perspective. J Clin Nurs, 23 (15-16), 2313-2322. doi:10.1111/jocn.12513

Boyatzis, R. E. (2009). Transforming qualitative information : thematic analysis and code development. Thousand Oaks [u.a.]: Sage.

Coelho, T., Santos, R., Paul, C., Gobbens, R. J., \& Fernandes, L. (2015). Portuguese version of the Tilburg Frailty Indicator: Transcultural adaptation and psychometric validation. Geriatr Gerontol Int, 15 (8), 951-960. doi:10.1111/ggi.12373

Creswell, J. W., \& Plano Clark, V. L. (2018). Designing and conducting mixed methods research.

De Jong Gierveld, J., \& Van Tilburg, T. (2010). The De Jong Gierveld short scales for emotional and social loneliness: tested on data from 7 countries in the UN generations and gender surveys. Eur J Ageing, 7 (2), 121-130. doi:10.1007/s10433-010-0144-6 
European Innovation Partnership on Active and Healthy Ageing. (2013). Specific Action on innovation in support of 'Personalized health management, starting with a Falls Prevention Initiative'. Retrieved from https://ec.europa.eu/eip/ageing/sites/eipaha/files/library/51a44f911f647_a2_action_pl an.pdf

Foss, C., \& Ellefsen, B. (2002). The value of combining qualitative and quantitative approaches in nursing research by means of method triangulation. $J$ Adv Nurs, 40 (2), 242-248.

Franse, C. B., van Grieken, A., Alhambra-Borras, T., Valia-Cotanda, E., van Staveren, R., Rentoumis, T., . . Raat, H. (2018). The effectiveness of a coordinated preventive care approach for healthy ageing (UHCE) among older persons in five European cities: A pre-post controlled trial. Int J Nurs Stud, 88, 153-162.

doi:10.1016/j.ijnurstu.2018.09.006

Franse, C. B., Voorham, A. J. J., van Staveren, R., Koppelaar, E., Martijn, R., Valia-Cotanda, E., . . Raat, H. (2017). Evaluation design of Urban Health Centres Europe (UHCE): preventive integrated health and social care for community-dwelling older persons in five European cities. BMC Geriatr, 17 (1), 209. doi:10.1186/s12877-017-0606-1

Gobbens, R. J., van Assen, M. A., Luijkx, K. G., \& Schols, J. M. (2012). The predictive validity of the Tilburg Frailty Indicator: disability, health care utilization and quality of life in a population at risk. Gerontologist, 52 (5), 619-631. doi:gnr135 [pii]

10.1093/geront/gnr135

Gobbens, R. J., van Assen, M. A., Luijkx, K. G., Wijnen-Sponselee, M. T., \& Schols, J. M. (2010). The Tilburg Frailty Indicator: psychometric properties. J Am Med Dir Assoc, 11 (5), 344-355. doi:10.1016/j.jamda.2009.11.003

This article is protected by copyright. All rights reserved. 
Hajek, A., \& Konig, H. H. (2017). The association of falls with loneliness and social exclusion: evidence from the DEAS German Ageing Survey. BMC Geriatr, 17 (1), 204. doi:10.1186/s12877-017-0602-5

Harrell, M. C., Bradley, M., National Defense Research, I., \& Rand, C. (2009). Data collection methods : semi-structured interviews and focus groups.

Herrera-Badilla, A., Navarrete-Reyes, A. P., Amieva, H., \& Avila-Funes, J. A. (2015). Loneliness is associated with frailty in community-dwelling elderly adults. $J \mathrm{Am}$ Geriatr Soc, 63 (3), 607-609. doi:10.1111/jgs.13308

Huss, A., Stuck, A. E., Rubenstein, L. Z., Egger, M., \& Clough-Gorr, K. M. (2008). Multidimensional preventive home visit programs for community-dwelling older adults: a systematic review and meta-analysis of randomized controlled trials. $J$ Gerontol A Biol Sci Med Sci, 63 (3), 298-307. doi:63/3/298 [pii]

Kringos, D. S., Boerma, W. G. W., Hutchinson, A., Saltman, R. B., European Observatory on Health, S., \& Policies. (2015). Building primary care in a changing Europe.

Legare, F., Stacey, D., Pouliot, S., Gauvin, F. P., Desroches, S., Kryworuchko, J., . . . Graham, I. D. (2011). Interprofessionalism and shared decision-making in primary care: a stepwise approach towards a new model. J Interprof Care, 25 (1), 18-25. doi:10.3109/13561820.2010.490502

Markle-Reid, M., Browne, G., \& Gafni, A. (2013). Nurse-led health promotion interventions improve quality of life in frail older home care clients: Lessons learned from three randomized trials in Ontario, Canada. J Eval Clin Pract, 19 (1), 118-131.

Mayo-Wilson, E., Grant, S., Burton, J., Parsons, A., Underhill, K., \& Montgomery, P. (2014). Preventive home visits for mortality, morbidity and institutionalization in older adults: 
a systematic review and meta-analysis. PLoS One, 9 (3), e89257.

doi:10.1371/journal.pone.0089257

PONE-D-13-47215 [pii]

Metzelthin, S. F., Daniels, R., van Rossum, E., Cox, K., Habets, H., de Witte, L. P., \& Kempen, G. I. (2013). A nurse-led interdisciplinary primary care approach to prevent disability among community-dwelling frail older people: a large-scale process evaluation. Int J Nurs Stud, 50 (9), 1184-1196. doi:S0020-7489 (12)00458-0 [pii]

10.1016/j.ijnurstu.2012.12.016

Metzelthin, S. F., van Rossum, E., de Witte, L. P., Ambergen, A. W., Hobma, S. O., Sipers, W., \& Kempen, G. I. (2013). Effectiveness of interdisciplinary primary care approach to reduce disability in community dwelling frail older people: cluster randomised controlled trial. $B M J, 347$, f5264.

Mohler, R., Kopke, S., \& Meyer, G. (2015). Criteria for Reporting the Development and Evaluation of Complex Interventions in healthcare: revised guideline (CReDECI 2). Trials, 16, 204. doi:10.1186/s13063-015-0709-y

Morrison, A., Fan, T., Sen, S. S., \& Weisenfluh, L. (2013). Epidemiology of falls and osteoporotic fractures: a systematic review. Clinicoecon Outcomes Res, 5, 9-18. doi:10.2147/CEOR.S38721

ceor-5-009 [pii]

Muhlack, D. C., Hoppe, L. K., Weberpals, J., Brenner, H., \& Schottker, B. (2017). The Association of Potentially Inappropriate Medication at Older Age With Cardiovascular Events and Overall Mortality: A Systematic Review and MetaAnalysis of Cohort Studies. J Am Med Dir Assoc, 18 (3), 211-220. doi:10.1016/j.jamda.2016.11.025

This article is protected by copyright. All rights reserved. 
Muntinga, M. E., van Leeuwen, K. M., Jansen, A. P. D., Nijpels, G., Schellevis, F. G., \& Abma, T. A. (2016). The Importance of Trust in Successful Home Visit Programs for Older People. Glob Qual Nurs Res, 3, 2333393616681935. doi:10.1177/2333393616681935

Navickas, R., Petric, V. K., Feigl, A. B., \& Seychell, M. (2016). Multimorbidity: What do we know? What should we do? J Comorb, 6 (1), 4-11. doi:10.15256/joc.2016.6.72

Nolte, E., Knai, C., McKee, M., Organizacion Mundial de la, S., European Obsrvatory on Health, S., \& Policies. (2009). Managing chronic conditions : experience in eight countries. Copenhagen: World Health Organization on behalf of the European Observatory on Health Systems and Policies.

Onder, G., Liperoti, R., Soldato, M., Carpenter, I., Steel, K., Bernabei, R., \& Landi, F. (2007). Case management and risk of nursing home admission for older adults in home care: results of the AgeD in HOme Care Study. J Am Geriatr Soc, 55 (3), 439444. doi:JGS1079 [pii]

10.1111/j.1532-5415.2007.01079.x

Organisation for Economic, C.-o., \& Development. (1999). Classifying educational programmes : manual for ISCED-97 implementation in OECD countries. Paris: Organisation for Economic Co-operation and Development.

Poot, A. J., Caljouw, M. A., Waard, C. S., Wind, A. W., \& Gussekloo, J. (2016). Satisfaction in Older Persons and General Practitioners during the Implementation of Integrated Care. PLoS One, 11 (10), e0164536. doi:10.1371/journal.pone.0164536

Ruiz, S., Snyder, L. P., Rotondo, C., Cross-Barnet, C., Colligan, E. M., \& Giuriceo, K. (2017). Innovative Home Visit Models Associated With Reductions In Costs, 
Hospitalizations and Emergency Department Use. Health Aff (Millwood), 36 (3), 425432. doi:10.1377/hlthaff.2016.1305

Saunders, R. P., Evans, M. H., \& Joshi, P. (2005). Developing a process-evaluation plan for assessing health promotion program implementation: a how-to guide. Health Promot Pract, 6 (2), 134-147. doi:6/2/134 [pii]

$10.1177 / 1524839904273387$

Smit, L. C., Schuurmans, M. J., Blom, J. W., Fabbricotti, I. N., Jansen, A. P. D., Kempen, G., ... Bleijenberg, N. (2017). Unravelling complex primary-care programs to maintain independent living in older people: a systematic overview. J Clin Epidemiol. doi:10.1016/j.jclinepi.2017.12.013

Steckler, A. B. L. L. (2002). Process evaluation for public health interventions and research. San Francisco, Calif.: Jossey-Bass.

Twisk, J. W. R. (2013). Applied multilevel analysis a practical guide. Cambridge: Cambridge University Press.

Uchmanowicz, I., Jankowska-Polanska, B., Loboz-Rudnicka, M., Manulik, S., LobozGrudzien, K., \& Gobbens, R. J. (2014). Cross-cultural adaptation and reliability testing of the Tilburg Frailty Indicator for optimizing care of Polish patients with frailty syndrome. Clin Interv Aging, 9, 997-1001. doi:10.2147/CIA.S64853

cia-9-997 [pii]

United Nations Department of Economic and Social affairs. (2017). World Population Prospects. Retrieved from https://esa.un.org/unpd/wpp/dataquery/

van Kempen, J. A., Robben, S. H., Zuidema, S. U., Olde Rikkert, M. G., Melis, R. J., \& Schers, H. J. (2012). Home visits for frail older people: a qualitative study on the 
needs and preferences of frail older people and their informal caregivers. Br J Gen Pract, 62 (601), e554-560. doi:10.3399/bjgp12X653606

van Oyen, H., Van der Heyden, J., Perenboom, R., \& Jagger, C. (2006). Monitoring population disability: evaluation of a new Global Activity Limitation Indicator (GALI). Soz Praventivmed, 51 (3), 153-161.

Veiligheid.nl. Fall risk test Retrieved from http://www.veiligheid.nl/voorlichtingsmateriaal/valanalyse-inventarisatie-valrisico65-door-de-eerstelijnszorg

Wind, A. W., Numans, M. E., Blom, J. W., Den Elzen, W. P. J., Gussekloo, J., Melis, R. J. F., . . consortium, T.-M. r. (2018). Effectiveness and cost-effectiveness of proactive and multidisciplinary integrated care for older people with complex problems in general practice: an individual participant data meta-analysis. Age and Ageing, 47 (5), 705-714. doi:10.1093/ageing/afy091

Yang, K., \& Victor, C. (2011). Age and loneliness in 25 European nations. Ageing and Society, 31 (8), 1368-1388. doi:doi:10.1017/S0144686X1000139X

This article is protected by copyright. All rights reserved. 
Table 1. Context of the cities involved in UHCE

\begin{tabular}{|c|c|c|c|c|c|}
\hline & Manchester, UK & Pallini, GR & Rijeka, HR & Rotterdam, NL & Valencia, ES \\
\hline $\begin{array}{l}\text { Location } \\
\text { UHCE } \\
\text { approach }\end{array}$ & $\begin{array}{l}\text { General practices } \\
\text { in Tameside and } \\
\text { Glossop districts. }\end{array}$ & $\begin{array}{l}\text { Municipality/senior } \\
\text { centres Pallini }\end{array}$ & $\begin{array}{l}\text { General } \\
\text { practices in } \\
\text { Western Rijeka. }\end{array}$ & $\begin{array}{l}\text { Primary health } \\
\text { center in } \\
\text { Ommoord } \\
\text { neighbourhood. }\end{array}$ & $\begin{array}{l}\text { Primary health } \\
\text { center in Nou } \\
\text { Moles } \\
\text { neighbourhood }\end{array}$ \\
\hline Assessment & $\begin{array}{l}\text { At home by } \\
\text { trained assistant }\end{array}$ & $\begin{array}{l}\text { At senior/health } \\
\text { centre by health } \\
\text { professional }\end{array}$ & $\begin{array}{l}\text { At home by } \\
\text { community } \\
\text { nurse }\end{array}$ & $\begin{array}{l}\text { At home by } \\
\text { trained assistant }\end{array}$ & $\begin{array}{l}\text { At home by } \\
\text { trained assistant }\end{array}$ \\
\hline $\begin{array}{l}\text { Care } \\
\text { coordinator }\end{array}$ & $\begin{array}{l}\text { Trained assistant } \\
\text { supervised by GP }\end{array}$ & $\begin{array}{l}\text { Health professional or } \\
\text { social worker }\end{array}$ & $\begin{array}{l}\text { Community } \\
\text { nurse }\end{array}$ & $\begin{array}{l}\text { Geriatric nurse } \\
\text { practitioner }\end{array}$ & $\begin{array}{l}\text { Trained assistant } \\
\text { supervised by GP }\end{array}$ \\
\hline $\begin{array}{l}\text { Type of care } \\
\text { in care- } \\
\text { pathways }\end{array}$ & $\begin{array}{l}\text { Multiple per } \\
\text { pathway; e.g. } \\
\text { home adjustment } \\
\text { by OT, walking } \\
\text { group by } \\
\text { volunteers (falls); } \\
\text { medication review } \\
\text { by GP } \\
\text { (polypharmacy); } \\
\text { buddying services } \\
\text { by volunteers } \\
\text { (loneliness); } \\
\text { further care by GP } \\
\text { (frailty). }\end{array}$ & $\begin{array}{l}\text { Group based } \\
\text { endurance and } \\
\text { balance training by PE } \\
\text { (falls); self-managed } \\
\text { medication } \\
\text { adherence App } \\
\text { supported by } \\
\text { physician } \\
\text { (polypharmacy); } \\
\text { support groups by } \\
\text { psychologist } \\
\text { (loneliness); further } \\
\text { care by physician } \\
\text { (frailty). }\end{array}$ & $\begin{array}{l}\text { Group based } \\
\text { balance and } \\
\text { strength training } \\
\text { by PT (falls and } \\
\text { frailty); self- } \\
\text { managed } \\
\text { medication } \\
\text { adherence App } \\
\text { (polypharmacy); } \\
\text { social group } \\
\text { activities } \\
\text { (loneliness). }\end{array}$ & $\begin{array}{l}\text { Multiple per } \\
\text { pathway; e.g. } \\
\text { physiotherapy } \\
\text { by PT (falls); } \\
\text { medication } \\
\text { review by } \\
\text { pharmacist } \\
\text { (polypharmacy); } \\
\text { social activities } \\
\text { (loneliness); } \\
\text { further care by } \\
\text { GP (frailty). }\end{array}$ & $\begin{array}{l}\text { Group based } \\
\text { balance and } \\
\text { strength training } \\
\text { by PT (falls and } \\
\text { frailty), } \\
\text { medication review } \\
\text { according to } \\
\text { national protocol } \\
\text { by GP } \\
\text { (polypharmacy), } \\
\text { social support } \\
\text { group led by social } \\
\text { worker } \\
\text { (loneliness). }\end{array}$ \\
\hline $\begin{array}{l}\text { Care existing } \\
\text { or newly } \\
\text { developed }\end{array}$ & $\begin{array}{l}\text { All existing; } \\
\text { offered by local } \\
\text { charity } \\
\text { organisation and } \\
\text { according to } \\
\text { practice GP }\end{array}$ & All newly developed & $\begin{array}{l}\text { Falls, frailty and } \\
\text { polypharmacy } \\
\text { newly } \\
\text { developed. } \\
\text { Loneliness } \\
\text { existing services }\end{array}$ & $\begin{array}{l}\text { All existing, } \\
\text { medical care } \\
\text { according to } \\
\text { practice GP and } \\
\text { social care by } \\
\text { local } \\
\text { organizations }\end{array}$ & $\begin{array}{l}\text { Falls, frailty and } \\
\text { loneliness newly } \\
\text { developed. } \\
\text { Polypharmacy } \\
\text { existing protocol }\end{array}$ \\
\hline
\end{tabular}

Abbreviations: ES=Spain; GP=general practitioner; GR=Greece; HR=Croatia; NL=The Netherlands; OT=occupational therapist; PE=physical educator; PT=physical therapist; UK=United Kingdom.

This article is protected by copyright. All rights reserved. 
Table 2: Components of the process evaluation, related research questions and method of measurement

\begin{tabular}{llll}
\hline Component & Research question & Measurement & \\
\hline & & Log & Focus Questi Project \\
& & books groups onnaire register
\end{tabular}

Reach 1. What population was reached by UHCE approach?

1.1 How many persons accepted to participate in the UHCE approach?

1.2 What were characteristics of persons who were lost to follow-up between baseline and followup?

Dose delivered and received

2. What dose of the intervention was actually delivered and received by which participants?

2.1 To what extent were three stages of the UHCE $X$ approach (assessment, shared-decision making, carepathways) delivered to older persons?

2.2 What were characteristics of persons who did $\mathrm{X}$ not enroll in care-pathways?

2.3 What were reasons for non-enrolment in care-pathways?

\section{Satisfaction} and experience
3. What was the satisfaction and experience of main stakeholders involved in the UHCE approach?

3.1 Were older persons satisfied with the UHCE approach?

3.2 What benefits, barriers and improvements did older persons, informal caregivers and professionals report?
X

Abbreviations; UHCE=Urban Health Centres Europe

This article is protected by copyright. All rights reserved. 
Table 3. Reach and dose delivered for each stage of the UHCE approach

\begin{tabular}{|c|c|c|c|c|c|c|}
\hline Stage & $\begin{array}{l}\text { Total } \\
\text { N (\%) }\end{array}$ & $\begin{array}{l}\text { Manchester } \\
\text { N (\%) }\end{array}$ & $\begin{array}{l}\text { Pallini } \\
\text { N (\%) }\end{array}$ & $\begin{array}{l}\text { Rijeka } \\
\text { N (\%) }\end{array}$ & $\begin{array}{l}\text { Rotterdam } \\
\text { N (\%) }\end{array}$ & $\begin{array}{l}\text { Valencia } \\
\text { N (\%) }\end{array}$ \\
\hline Invited for UHCE approach & 2825 & 1166 & 500 & 277 & 512 & 370 \\
\hline Completed baseline health assessment & $1215(40.3)$ & $274(23.5)$ & 190(38.0) & 249(89.9) & $243(47.5)$ & 259(70.0) \\
\hline Completed follow-up questionnaire & $986(81.2)$ & $212(77.4)$ & 154(81.1) & $221(88.8)$ & 192(79.0) & 207(79.9) \\
\hline Any indication as in UHCE template ${ }^{a}$ & $794(80.5)$ & $173(81.6)$ & $132(85.7)$ & $190(86.0)$ & $147(76.6)$ & $152(73.4)$ \\
\hline Fall risk indication & $502(50.9)$ & 114(53.8) & $69(44.8)$ & $129(58.4)$ & $85(44.3)$ & $105(50.7)$ \\
\hline Polypharmacy indication & $495(50.2)$ & 132(62.3) & $83(53.9)$ & $100(45.2)$ & $104(54.2)$ & $76(36.7)$ \\
\hline Loneliness indication & $280(28.6)$ & $26(12.4)$ & $62(40.5)$ & $102(46.6)$ & $46(24.1)$ & $44(21.3)$ \\
\hline Frailty/medical indication & $532(54.0)$ & $100(47.2)$ & $105(68.2)$ & $140(63.6)$ & $81(42.2)$ & $106(51.2)$ \\
\hline Any indication reported as in logbooks ${ }^{a}$ & $831(85.6)$ & $157(74.1)$ & 144(93.5) & $220(100)$ & $145(81.5)$ & 165(79.7) \\
\hline Fall risk indication & $549(56.5)$ & $114(53.8)$ & $74(48.1)$ & $168(76.4)$ & $75(42.1)$ & $118(57.0)$ \\
\hline Polypharmacy indication & $322(33.9)$ & $9(0.04)$ & $49(31.8)$ & $116(52.7)$ & $88(49.4)$ & $60(32.1)$ \\
\hline Loneliness indication & $464(47.8)$ & $89(42.0)$ & 109(70.8) & $153(69.5)$ & $46(25.8)$ & $58(31.0)$ \\
\hline Frailty/medical indication & $314(33.0)$ & $101(47.6)$ & $71(46.1)$ & $165(74.7)$ & $83(46.6)$ & $67(32.4)$ \\
\hline Shared decision making ${ }^{a}$ & $969(98.3)$ & $212(100)$ & $154(100)$ & $220(99.5)$ & 176(91.7) & 207(100) \\
\hline Enrollment any care-pathway ${ }^{a}$ & $520(52.7)$ & $47(22.2)$ & $112(72.7)$ & $220(99.5)$ & $28(14.6)$ & $113(54.6)$ \\
\hline Enrollment Falls care-pathway & $278(28.6)$ & 39(18.4) & $24(15.6)$ & $143(65.0)$ & $0^{b}$ & $72(34.8)$ \\
\hline Enrollment Polypharmacy care-pathway & $130(13.7)$ & $2(0.9)$ & $46(29.9)$ & $22(10.0)$ & $5(2.8)^{b}$ & $55(29.4)$ \\
\hline Enrollment Loneliness care-pathway & $223(23.0)$ & $4(1.9)$ & $55(35.7)$ & $133(60.5)$ & $1(0.6)^{b}$ & $30(14.5)$ \\
\hline Enrollment Frailty/medical care-pathway & $94(9.9)$ & $16(7.5)$ & $53(34.4)$ & NA & $25(14.0)$ & NA \\
\hline
\end{tabular}

Abbreviations: NA=not applicable; UHCE=Urban Health Centres Europe. Missing items: Indication for care-pathway as in UHCE template; Frailty =1, Loneliness =7; Indication for care-pathway as reported in logbooks; Frailty=35, Falls=15,

Polypharmacy=35, Loneliness=15; Enrollment in any care-pathway=4; Frailty=24, Falls=4, Polypharmacy=24, Loneliness=4. a) The percentage reported is of the participants who completed the follow-up questionnaire and with complete information for the item; b) These are persons finishing the care-pathway; respectively 23, 90 and 7 persons followed the falls, polypharmacy and loneliness care-pathways without formally finishing it.

This article is protected by copyright. All rights reserved. 
Table 4. Multilevel logistic regression on factors associated with non-enrolment among persons enrolled in the care-pathway and persons not enrolled in the care-pathway who had an indication for the care-pathway.

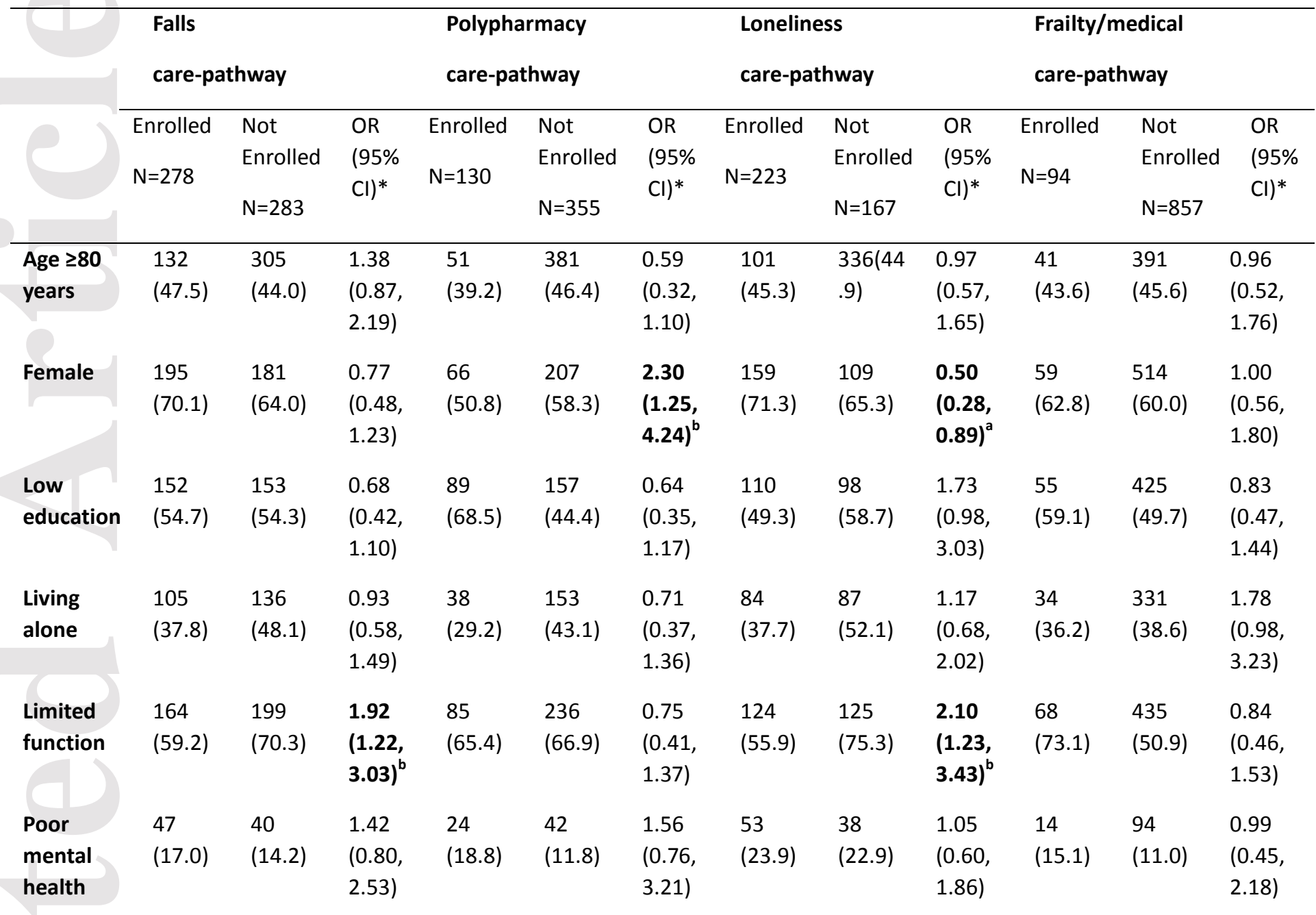

*Values are derived from random-intercept multilevel logistic regression models adjusted for clustering by city and adjusted for age, gender, education, living situation, function and mental health. $a=P$-value $<0.05 ; b=P$-value $<0.01$. Missing items: falls care-pathway; low education=1, limited foundation=1, poor mental health=2; polypharmacy care-pathway; low education=1, limited foundation=2, poor mental health=2; loneliness care-pathway; limited foundation=2, poor mental health=2; frailty/medical care-pathway; low education $=3$, limited foundation $=3$, poor mental health $=4$

This article is protected by copyright. All rights reserved. 
Table 5. Reasons participants reported why they did not enroll in care-pathways $(N=173)$

\begin{tabular}{ll}
\hline Reason reported* & $\mathbf{N}(\%)$ \\
\hline Wants to deal with it themselves & $49(28.3)$ \\
Does not want & $47(27.2)$ \\
Involved other care or exercise & $38(22.0)$ \\
Health problems prevent participation & $20(11.6)$ \\
Interested but not yet applied & $15(8.7)$ \\
Feels too healthy & $9(5.2)$ \\
Too far/transportation difficulties & $9(5.2)$ \\
Too busy to participate & $6(3.5)$ \\
Moved & $2(1.2)$ \\
Care for someone, too busy & $2(1.2)$
\end{tabular}

*Multiple reasons could be reported per person

This article is protected by copyright. All rights reserved. 
Table 6. Satisfaction among older persons with the UHCE approach

\begin{tabular}{|c|c|c|c|c|c|c|}
\hline Satisfaction statements & Total & $\begin{array}{l}\text { Manche } \\
\text { ster }\end{array}$ & Pallini & Rijeka & $\begin{array}{l}\text { Rotterd } \\
\text { am }\end{array}$ & Valencia \\
\hline \multicolumn{7}{|l|}{ Agree or strongly agree; n/N (\%) } \\
\hline I can benefit from the health assessment & $\begin{array}{l}630 / 767 \\
(82.1)\end{array}$ & $\begin{array}{l}167 / 212 \\
(78.8)\end{array}$ & $\begin{array}{l}76 / 104 \\
(73.1)\end{array}$ & $\begin{array}{l}194 / 221 \\
(87.8)\end{array}$ & $\begin{array}{l}13 / 23 \\
(56.5)\end{array}$ & $\begin{array}{l}180 / 207 \\
(87.0)\end{array}$ \\
\hline The health assessment was worth the time and effort & $\begin{array}{l}650 / 761 \\
(85.4)\end{array}$ & $\begin{array}{l}189 / 211 \\
(89.6)\end{array}$ & $\begin{array}{l}74 / 99 \\
(74.7)\end{array}$ & $\begin{array}{l}192 / 221 \\
(86.9)\end{array}$ & $\begin{array}{l}15 / 23 \\
(65.2)\end{array}$ & $\begin{array}{l}180 / 207 \\
(87.0)\end{array}$ \\
\hline I had a say in decisions about my health & $\begin{array}{l}372 / 474 \\
(78.5)\end{array}$ & $\begin{array}{l}2 / 3 \\
(66.7)\end{array}$ & $\begin{array}{l}65 / 97 \\
(67.0)\end{array}$ & $\begin{array}{l}199 / 221 \\
(90.0)\end{array}$ & $\begin{array}{l}16 / 23 \\
(69.6)\end{array}$ & $\begin{array}{l}90 / 130 \\
(69.2)\end{array}$ \\
\hline I am satisfied with the care I received & $\begin{array}{l}433 / 532 \\
(81.4)\end{array}$ & $\begin{array}{l}5 / 5 \\
(100)\end{array}$ & $\begin{array}{l}75 / 111 \\
(67.6)\end{array}$ & $\begin{array}{l}191 / 221 \\
(86.4)\end{array}$ & $\begin{array}{l}15 / 23 \\
(65.2)\end{array}$ & $\begin{array}{l}146 / 171 \\
(85.4)\end{array}$ \\
\hline
\end{tabular}

\section{Scale 1-10; mean $\pm S D$}

I am satisfied with the UHCE approach (scale 1-10) $\quad 8.3 \pm 1.9 \quad 9.3 \pm 1.2 \quad 6.5 \pm 2.4 \quad 8.3 \pm 1.8 \quad 7.9 \pm 0.9 \quad 8.8 \pm 1.5$

* Missing/not applicable: Benefit from health assessment=219; Worth time and effort=225; Results discussed with me=622; Had a say in decisions=512; Satisfied with care=454; Satisfied UHCE approach=188.

This article is protected by copyright. All rights reserved. 


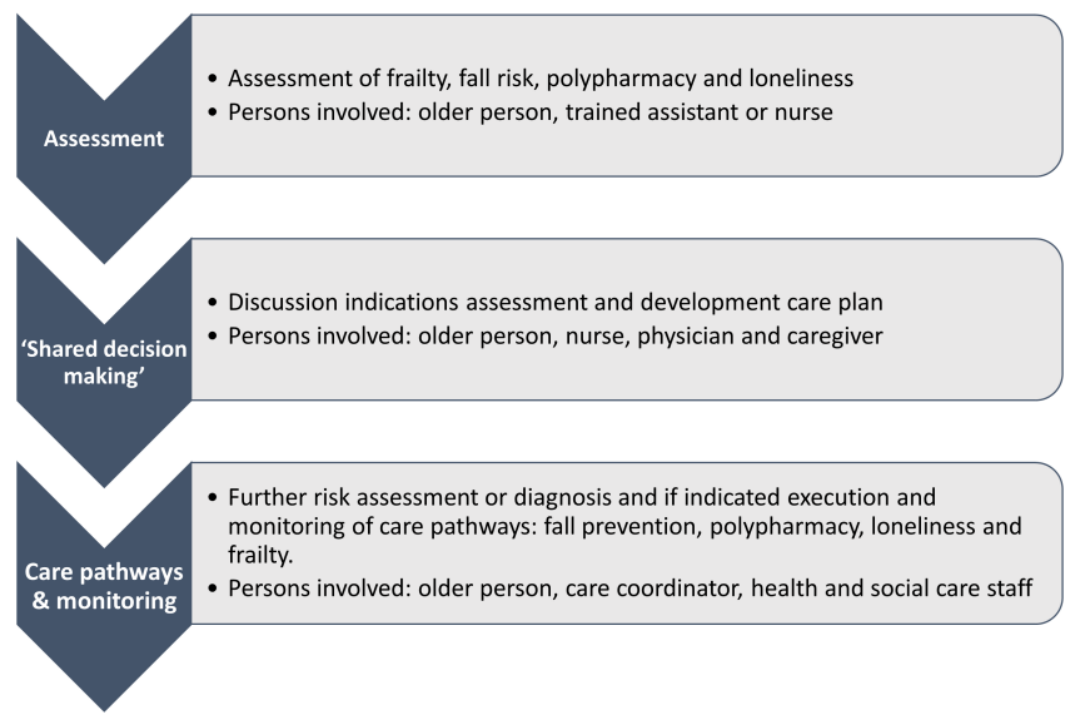

The UHCE approach (from Franse et al., 2017)

This article is protected by copyright. All rights reserved. 